This item was submitted to Loughborough's Research Repository by the author.

Items in Figshare are protected by copyright, with all rights reserved, unless otherwise indicated.

\title{
Analysis of electricity consumption for lighting and small power in office buildings
}

PLEASE CITE THE PUBLISHED VERSION

http://www.cibse.org/content/cibsesymposium2011/Paper078.pdf

PUBLISHER

CIBSE

VERSION

AM (Accepted Manuscript)

LICENCE

CC BY-NC-ND 4.0

\section{REPOSITORY RECORD}

Buswell, Richard A., Anna Carolina Kossmann de Menezes, Andrew Cripps, and Dino Bouchlaghem. 2019. "Analysis of Electricity Consumption for Lighting and Small Power in Office Buildings". figshare. https://hdl.handle.net/2134/9433. 
This item was submitted to Loughborough's Institutional Repository (https://dspace.lboro.ac.uk/) by the author and is made available under the following Creative Commons Licence conditions.

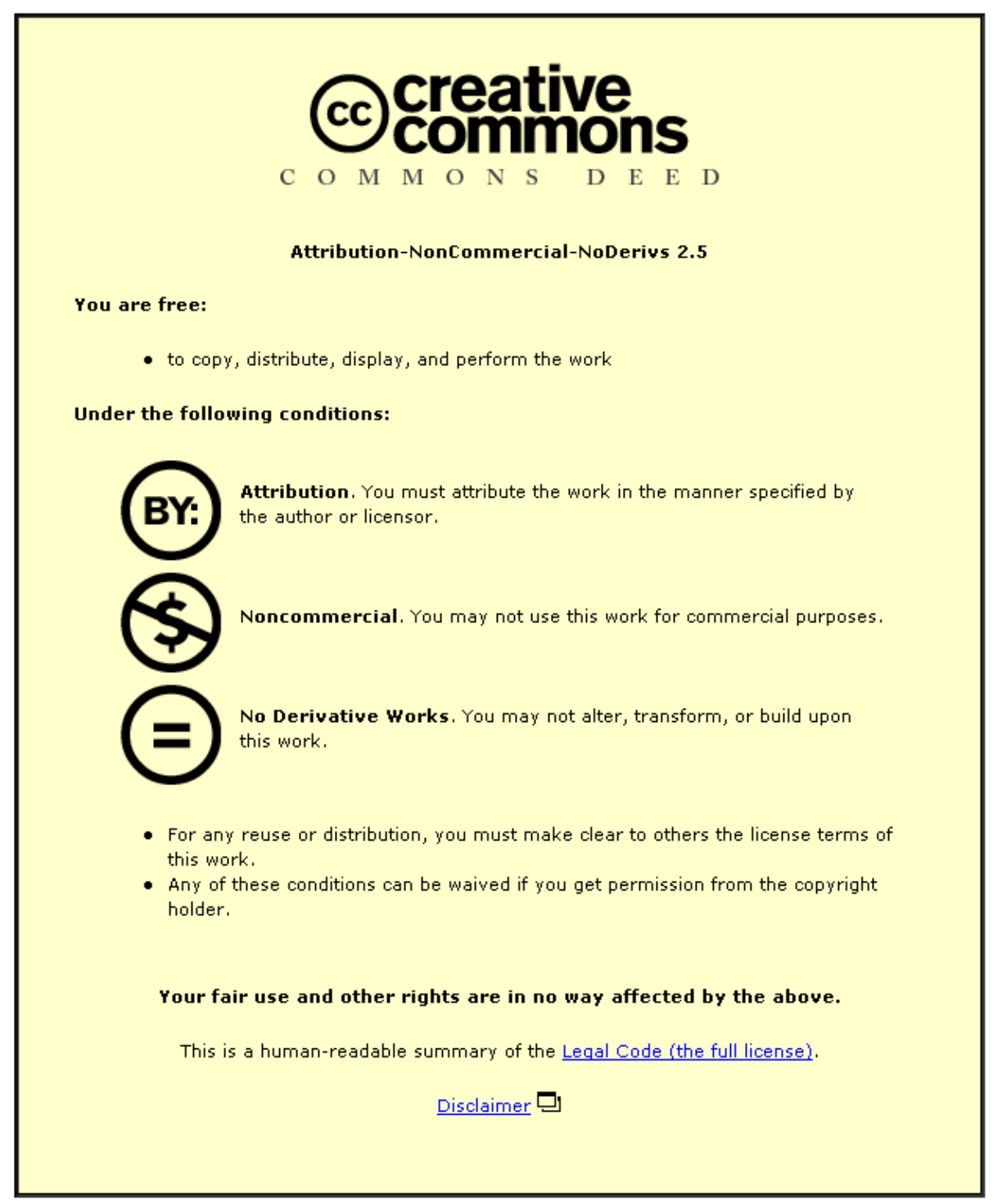

For the full text of this licence, please go to: http://creativecommons.org/licenses/by-nc-nd/2.5/ 


\title{
Analysis of Electricity Consumption for Lighting and Small Power in Office Buildings
}

Anna C. Menezes[1,2], Andrew Cripps[2], Dino Bouchlaghem[1], Richard Buswell[1]

[1] Loughborough University, UK [2] AECOM, UK

Anna.menezes@aecom.com

\begin{abstract}
There is significant evidence to suggest that buildings do not perform as well as expected, and this is commonly referred to as the 'performance gap'. Energy compliance calculations for Building Regulations in England and Wales do not include sources of energy consumption in buildings such as small power, catering, external lighting and vertical transportation (i.e. lifts and escalators). These so called 'unregulated' loads are therefore rarely included in building energy models, and the lack of feedback regarding the in-use performance of buildings makes it harder for designers to quantify their impact on the overall energy consumption of a building. Aiming to address these issues, this paper provides an analysis of monitored electricity consumption in two multi-tenanted office buildings, with one tenant in common in both buildings.
\end{abstract}

This paper focuses on tenant electricity consumption, including lighting and small power. Detailed analysis of the monitored data demonstrates significant variation between the electricity consumption of different tenants occupying the same building whilst performing similar activities. Elements such as lighting controls, hours of occupancy and management decisions are observed to have a significant impact on such variations. Further analysis of half-hourly energy consumption data is also provided, in addition to a detailed breakdown of small power energy consumption due to individual office equipment.

Future work will build on this study and aim to develop evidence based benchmarks for energy consumption in office buildings. It will include a 'tailoring' component allowing the benchmarks to be adjusted according to profiles of occupancy and management behaviour, as well as workstation density and the specification of energy consuming equipment. It is expected that such benchmarks will inform designers about the impact of each of these parameters on the measured energy consumption of buildings.

Keywords Performance gap, energy performance, offices, lighting, small power 


\subsection{Introduction}

With the increasing demand for more energy efficient buildings, the construction industry is faced with the challenge to ensure that energy efficiency is implemented beyond design predictions. However, there is extensive evidence to suggest that buildings are not performing as well as predicted. The PROBE studies (Postoccupancy Review of Buildings and their Engineering) investigated the performance of 23 non-domestic buildings previously featured as 'exemplar designs' in the Building Services Journal (BSJ) ${ }^{[1]}$. The research project ran from 1995 to 2002, highlighting the lack of feedback regarding the actual performance of buildings. It also brought to light the so called 'performance gap', suggesting that the actual energy consumption in buildings will usually be twice as much as predicted.

More recently, in 2008, the Royal Institute of British Architects (RIBA) and the Chartered Institution of Building Services Engineers (CIBSE) launched CarbonBuzz, a free online platform allowing practices to share and publish building energy consumption data anonymously ${ }^{[2]}$. It enables designers to compare predicted and actual energy use for their projects, whilst also allowing for comparison against benchmarks and data supplied by other participating practices. Figure 1 illustrates the gap between predicted and actual electricity consumption in three building types: general offices, schools and university campus. The graph depicts the median predicted and median actual electricity consumption for the buildings within the database, which are assumed to be broadly representative of each sector. As shown, the measured electricity demands are approximately $60 \%$ to $70 \%$ higher than predicted in both the schools and general offices, and over $85 \%$ higher than predicted in university campuses.

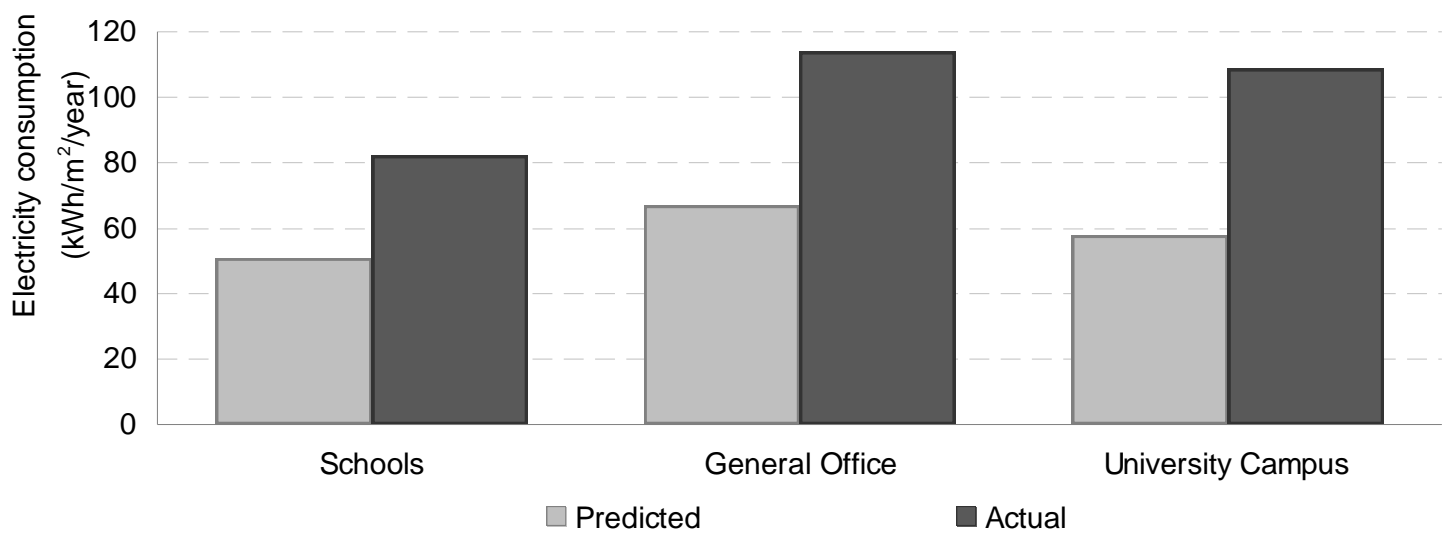

Figure 1: CarbonBuzz median energy use per sector - Predicted vs. Actual ${ }^{[3]}$

Previous work by the authors has highlighted that the causal factors for such discrepancies relate to both predictive and in-use performance, implying that current predictions tend to be unrealistically low, whilst actual energy performance is usually unnecessarily high ${ }^{[4]}$. However, the overall problem could be interpreted as an inability of both current modelling techniques and modellers to represent realistic operation of buildings through the use of inputs and parameters that are representative of occupied buildings in-use. This in turn can be associated with the lack of feedback regarding use and operation of buildings as well as the resulting energy consumption. Currently, there is a significant lack of information concerning the energy performance of our existing building stock ${ }^{[5]}$. A continued absence of such data is likely to lead to a progressive widening of the gap between theory and practice and a failure to achieve strategic goals ${ }^{[6]}$. 
In order to bridge this 'Performance Gap', further understanding on the impact of small power and other unregulated energy loads is crucial. Emphasis on these enduses allows for investigation of the impact of occupants and management behaviour and the resulting impact on the electricity consumption of different tenants. Variation in small power consumption is of particular interest to this study as small power is not currently included in the Building Regulations for England and Wales, and as such is not within the compliance modelling calculations. Aiming to address this issue, this paper provides an analysis of monitored data for electricity consumption due to lighting and small power in two office buildings in England.

\subsection{Methodology}

Taking a case study approach, this paper focuses on the energy performance of two multi-tenanted office buildings located in London and Bristol. The assessment concentrates on electricity consumption due to lighting, small power equipment and catering equipment, in line with the Energy Assessment and Reporting Methodology (EARM). This widely recognised methodology was originally developed for the PROBE studies and was later published by CIBSE as a technical memorandum (CIBSE TM22). This document describes a method for assessing the energy performance of an occupied building based on metered energy use, and includes a software implementation of the method. It can be used to identify underperforming buildings and systems, indicating the causes of poor performance and benchmarking procedures ${ }^{[7]}$. Figure 2 illustrates the underlying structure of the TM22 methodology, depicting the breakdown of energy consumption by end-uses (such as lighting, small power and ventilation) whilst highlighting the impact of low-level factors such as hours of use and equipment efficiency.

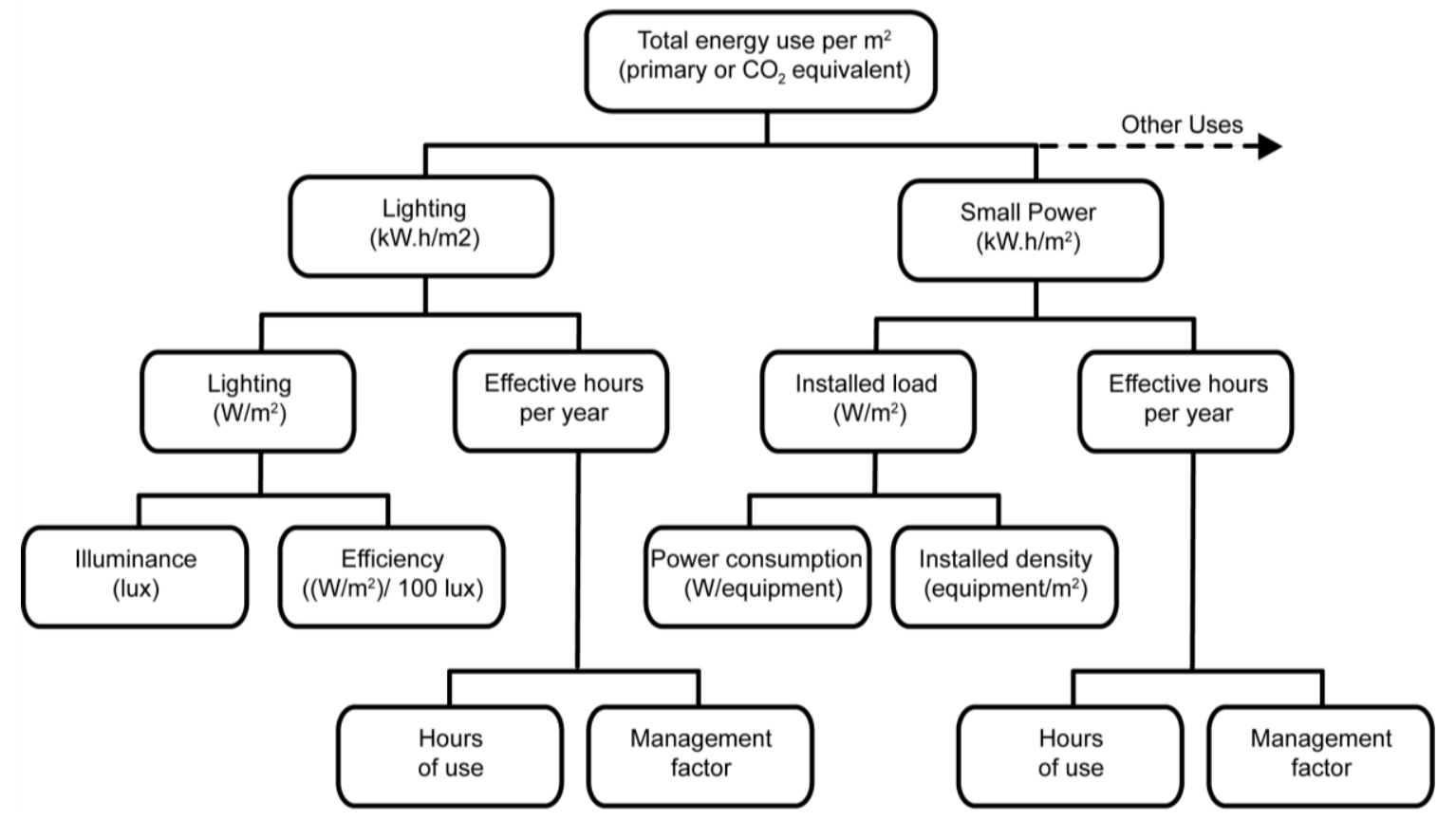

Figure 2: TM22 'Tree Diagram' illustrating the breakdown of energy use ${ }^{\text {[8] }}$

Considering the focus of the study was on lighting and small power, it was not necessary to undertake a full TM22 assessment of each building. However, in order to set the context for further in depth investigations, one of the buildings was assessed in full, highlighting the impact of lighting and small power on the overall electricity consumption of the building. Considering the building contains 28 zones occupied by 4 different tenants, assumptions were made with regards to the installed equipment and lighting in the tenant areas in order to facilitate this initial TM22 assessment. This was deemed appropriate as the purpose of this initial assessment 
was to provide context with regards to the energy use breakdown of different end uses. In the second building, electricity consumption due to building services was not considered and the assessment considered only the tenant electricity consumption (including lighting and small power due to office and catering equipment). In both buildings, the detailed TM22 assessment of lighting and small power in the tenant zones relied on studies of 'sample' zones occupied by different tenants.

\subsection{Building Description}

Building 1 is located in central London and accommodates the offices of four different companies throughout its six floors and basement. It includes an atrium that reaches all floors (except the basement). Each floor comprises mainly of open-plan office spaces with a treated floor area of approximately $2,000 \mathrm{~m}^{2}$. The ground floor houses a large reception and the basement houses meeting rooms and cellular offices. The building is fully air-conditioned, three rooftop air-handling units (AHUs) provide heating/cooling as well as fresh air to all floors and the atrium. A separate system provides heating for the basement, whilst fan coil units (FCUs) provide cooling to the meeting rooms and small individual offices

Figure 3 illustrates the metering strategy for the supply of electricity to Building 1. As shown, the landlord is responsible for the electricity consumed by all air conditioning equipment including the AHUs, FCUs, chillers, pumps and fans as well as the BMS and other control equipment. The lighting throughout the common areas of the building as well as the toilets is also supplied and maintained by the landlord. As such, the energy supplied for the landlord services is metered together, with no submetering for individual end-uses. Meanwhile, the electricity supplied to the tenants for lighting, small power equipment and catering in each of the floors is metered separately. A total of 28 sub-meters provide a further breakdown for each of the 4 zones in each floor: North-East (NE), Northwest (NW), Southeast (SE) and Southwest (SW).
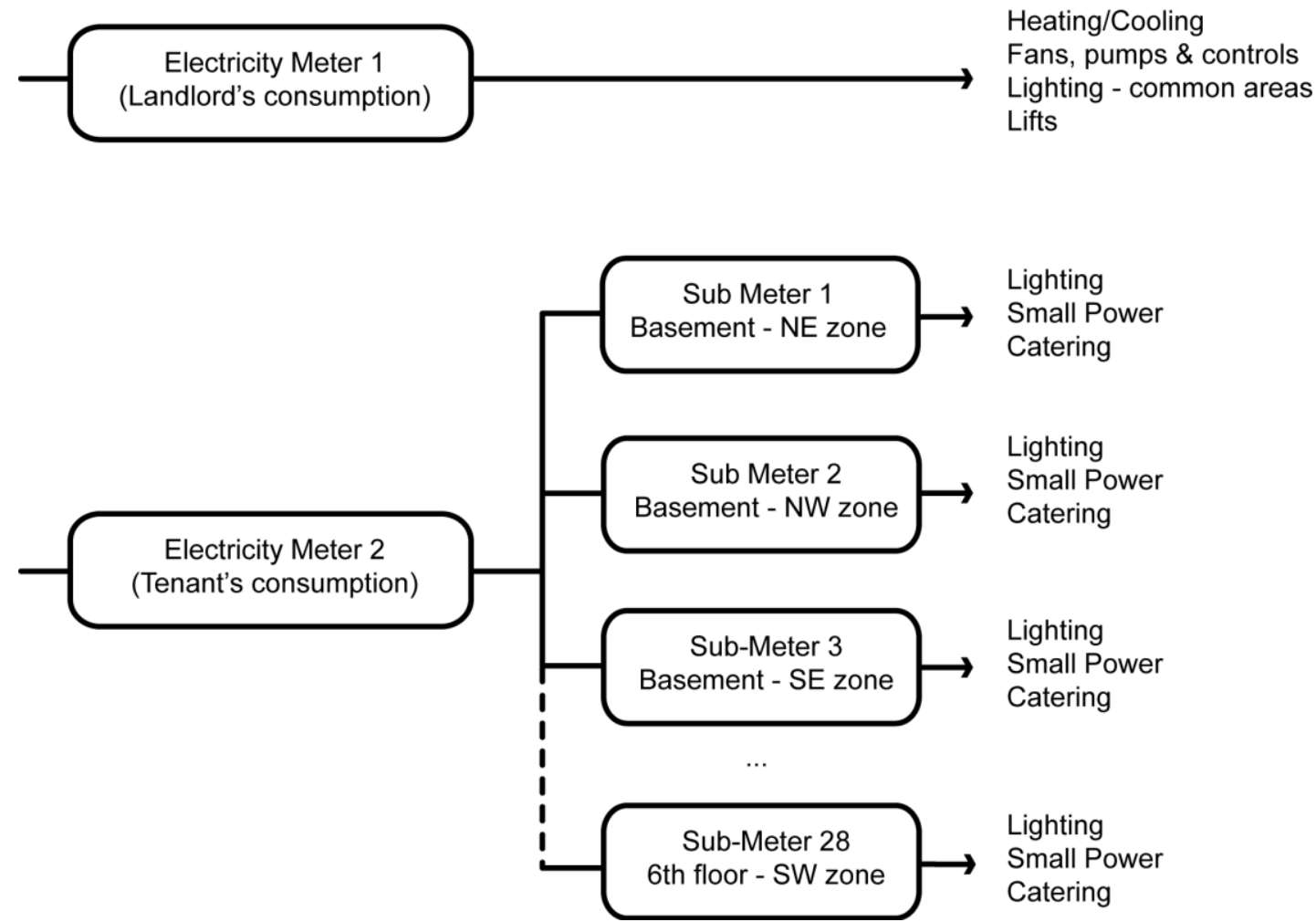

Figure 3: Metering strategy for the supply of electricity to Building 1 
Building 2 is located in Bristol city centre and accommodates offices of four different tenants over 4 floors. Each floor comprises mainly of open-plan office spaces with a treated floor area of approximately $3,500 \mathrm{~m}^{2}$. The ground floor houses a large reception and a cafe (for which the electricity and gas usage is metered separately from the rest of the building). The building is fully air-conditioned via FCUs, and has two atria with full height glazing providing natural lighting throughout the building.

Figure 4 illustrates the metering strategy for the supply of electricity to Building 2. Similarly to Building 1, the landlord is responsible for the electricity consumed by all air conditioning equipment as well as the BMS and lighting throughout the common areas of the building. Once again, the energy supplied for the landlord services is metered together, with no sub-metering for individual end-uses. Meanwhile, the electricity supplied to the tenants is not only sub-metered by zone, but also by end use, with lighting and small power having separate sub-meter in each individual zone. As such a total of 32 sub-meters provide a breakdown for lighting and small power in each of the 4 zones in each floor: Core 2.1, Core 2.2, Core 3 and Core 5.
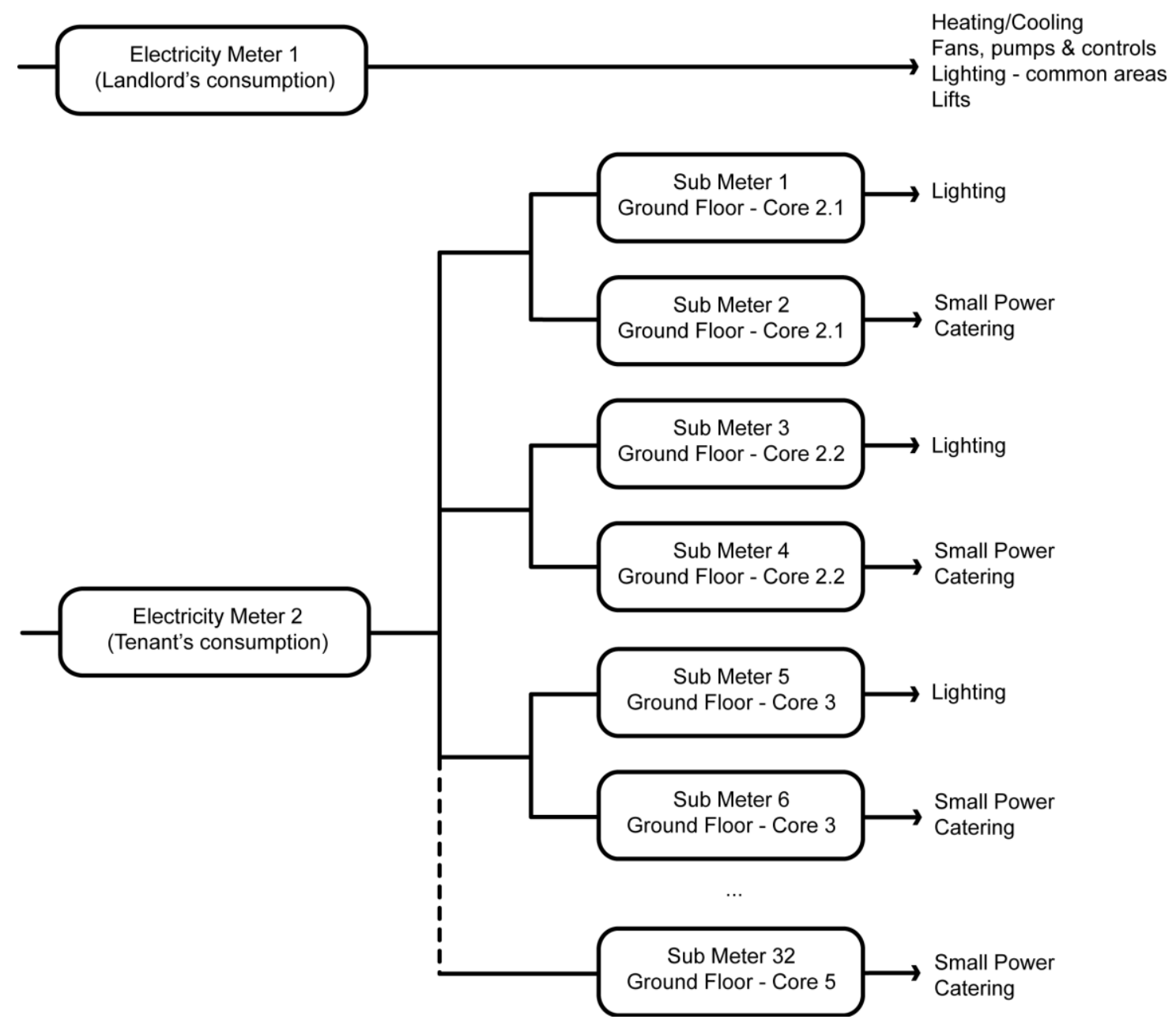

Figure 4: Metering strategy for the supply of electricity to Building 2

\subsection{Monitoring Process}

Monthly meter readings were taken and recorded over a one-year period for each of the electricity sub-meters in both buildings. In Building 1 this consisted of a single reading per zone (including lighting and small power) whereas in Building 2, two readings per zone were acquired due to the separate sub-metering for lighting and small power. Monthly and annual consumption data was then compiled for each of the tenants and normalised by floor area occupied. 
Portable 3-phase data loggers (SP Max ${ }^{[9]}$ ) were connected to the electricity supply in individual tenant zones in each of the buildings in order to monitor half hourly consumption. Focus was given to areas occupied by the same tenant in both buildings to establish any variation in the electricity consumption profile in different offices. In Building 2, interval data for lighting and small power were obtained simultaneously in different areas for fair comparison. Monitoring of sub-metered electricity was undertaken for approximately 1 month in each of the zones, and results were cross-checked against meter readings for verification.

Combined plug monitor / loggers (ZigBee Plogg ${ }^{[10]}$ ) were connected to individual small power office equipment such as laptops, computer screens and docking stations. These were also used to monitor the electricity consumption of catering equipment such as fridges, microwave ovens and coffee machines, and logged 5minute interval electricity consumption data over 1 week period. Averages during inuse, "stand-by" and "off" modes were calculated using the monitored data for each of the equipment. These values were then used to replace typical nameplate-rating inputs necessary for the successful completion of the TM22 assessment.

\subsection{Results \& Discussion}

Figure 5 illustrates the electricity consumption breakdown by end-use for Building 1 , providing context to further analysis of lighting and small power. It also illustrates the split between landlord and tenant consumption, demonstrating that the landlord is only responsible for $30 \%$ of the electricity used in the building, with the tenants being responsible for the remaining $70 \%$. As seen, lighting accounts for $24 \%$ of the annual electricity consumption, followed closely by small power, which accounts for $18 \%$ of the total. Server rooms are the single largest consumers of electricity in the building, almost equating to the combined consumption by fixed building services (i.e. chillers plus fans, pumps and controls). Note that the sub-metering of the server rooms in Building 1 include the electricity demand for running the servers themselves as well as the local cooling demands (usually met by split-system air conditioning units).

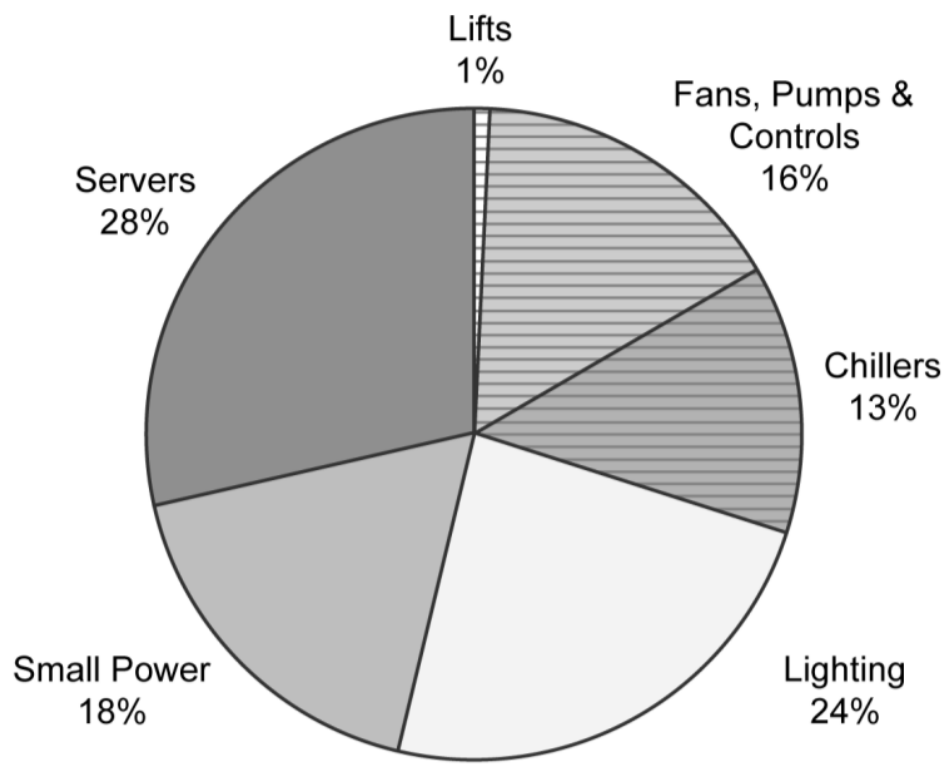

Tenant Consumption

Landlord Consumption

Figure 5: Electricity consumption breakdown by end-use in Building 1 


\subsection{Annual Electricity Consumption per Tenant}

Figure 6 illustrates the annual electricity consumption by each of the tenants in Building 1 (normalised by the floor area they occupy). This includes lighting and small power but excludes server rooms. It is worth noting that the lighting specification and controls are consistent throughout the entire building. This consists of a 'DALl' (Digital Addressable Lighting Interface) system whereby the installed fixtures have the capability of being controlled by a variety of factors such as daylight and/or motion sensors, to suit the need of the specific tenants. However, it is up to the individual tenants to adopt such control strategies by installing and commissioning the necessary sensors, otherwise the lighting strategy is limited to manual controls of the individual zones in the building. To date no tenants have taken advantage of the DALI system and thus they rely on manual switches to control their lighting levels.

With regards to catering facilities, all floors have provisions of similar size and nature (consisting mainly of an instant hot water heater, a microwave, a dishwasher and a full size fridge). Some floors have additional coffee machines and/or vending machines, and tenant $C$ has a large bar with multiple fridges on the ground floor. It is worth noting however, that variations in catering energy consumption can be largely due to hours of usage rather than intensity of installed equipment. Tenant $A$ for example have 2 microwave ovens in a single kitchen yet monitoring data has revealed that one of them is rarely used, hence having a second microwave oven has virtually no impact on their catering energy consumption.

In regards to small power, a fairly consistent volume of office equipment is present throughout the building. Despite their different nature of work, all 4 tenant companies have similar occupation densities and office equipment specifications. Most workstations consist of a computer screen, laptop and docking station as well as phone. Some workstations have individual desk lamps, personal fans and/or desktop printers. In addition, all floors have large printer/copiers (typically 6-8 per floor) as well as projectors and/or flat screen displays in meeting rooms.

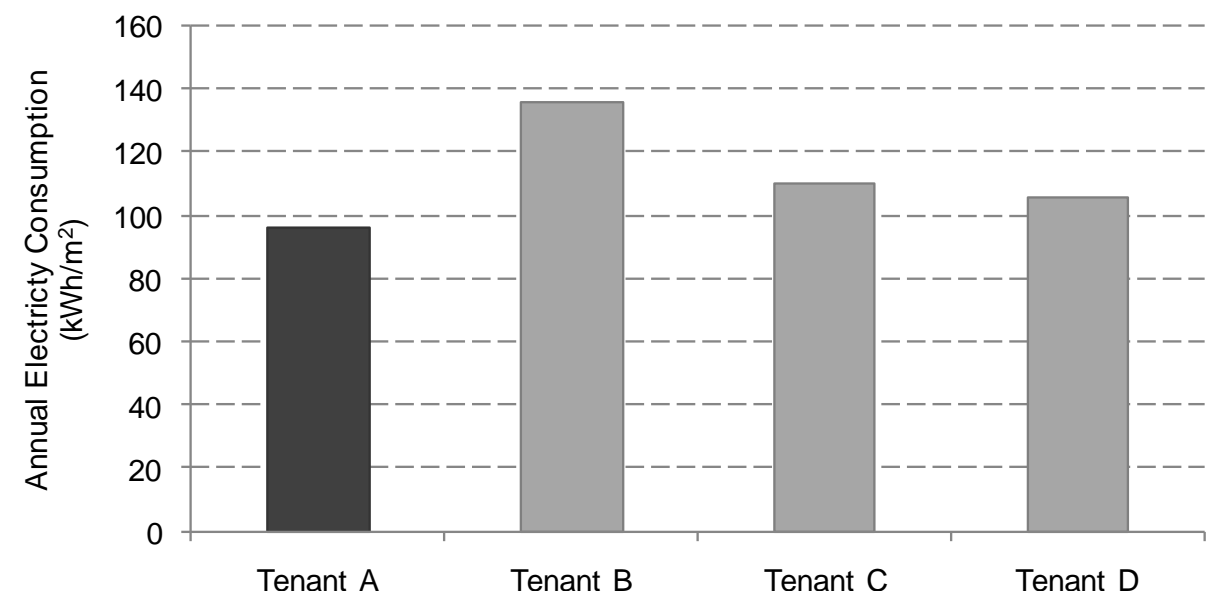

\section{Figure 6: Annual electricity consumption per tenant in Building 1}

As seen, the highest consumer (Tenant B) uses approximately $40 \%$ more electricity per year than the lowest consumer (Tenant $A$ ). Informal interviews with the building occupants uncovered a number of behavioural elements that could contribute to this significant variation. For example, employees of Tenant B are instructed to leave their computers on overnight for IT upgrades. As such, a large quantity of electricity is used outside the normal operating hours of the building, accounting for a significant portion of their overall consumption. Similarly, some employees of Tenant 
C often leave their computers on at the end of the day so that time-consuming tasks, such as high quality rendering, can be performed overnight. On the other hand, employees of Tenants $A$ and $D$ are encouraged to save energy by turning off their computers and screens at the end of the day. Tenant $A$ has also trained their facilities co-ordinators to switch off printer/copiers and non-essential catering equipment such as coffee machines at the end of each day.

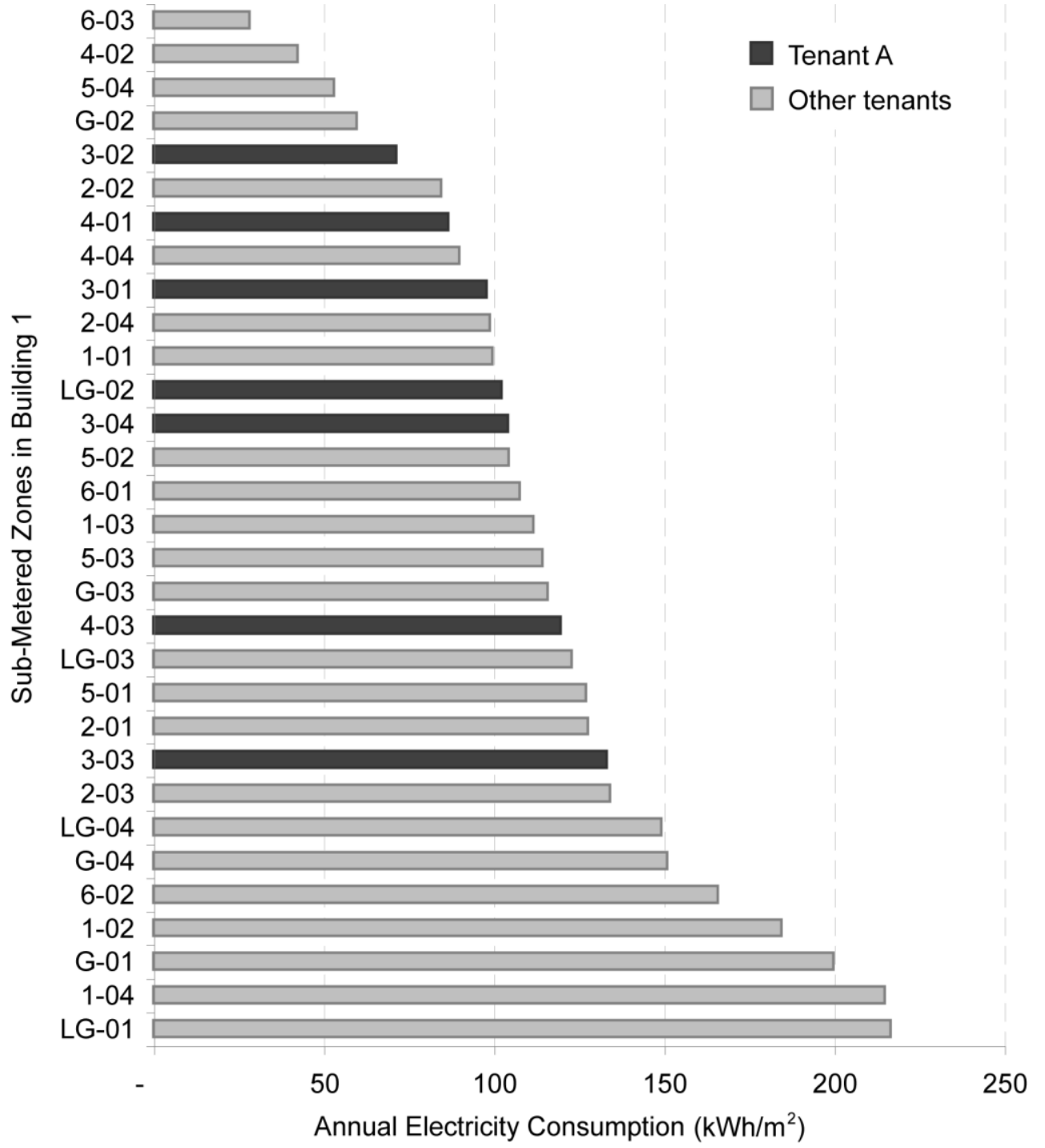

Figure 7: Electricity consumption in individual zones of Building 1

Figure 7 illustrates the electricity consumption in each of the sub-metered zones within Building 1 (normalised by floor area). The dark grey bars represent the zones occupied by Tenant A. Here, the highest consuming zones (3-03 and 4-03) are occupied in a very similar manner, both being located on the South-East corner of the building, containing high density of workstations as well as substantial printing facilities. Meanwhile, some of Tenant A's least consuming zones (3-01 and 4-01) are also very similar in layout, this time with lower workstation density due to the existence of a catering kitchen and small reception area on each of the floors. Despite the fact that both catering kitchens contain equipment that consume large quantities of electricity (such as dishwashers, instant water heaters and microwave ovens) these are only used sparingly. In addition, the seating areas in the catering kitchens occupy a significant proportion of the floor area in each of the zones and virtually no small power electricity in consumed in those areas. Zone 3-02 has surprisingly low electricity consumption considering it has no large areas of seating 
such as in zones 3-01 and 4-01. However, the zone has no printing facilities and it also contains a small meeting room, which reduces the overall workstation density of the zone. Meanwhile, zone LG-02 consists mainly of meeting rooms, most of which are heavily equipped with multimedia equipment for presentations and conference calls. These meeting rooms are usually fully booked and fairly high electricity consumption would suggest that the use of small power is fairly high in this zone (which might otherwise be expected to be a low consuming zone).

Figure 8 illustrates the annual electricity consumption by each of the tenants in Building 2 (normalised by the floor area they occupy). Once again it includes lighting and small power but excludes server rooms. Similarly to Building 1, the lighting specification and controls are consistent throughout the entire building and installed equipment is of a similar nature and quantity. It is worth mentioning however, that the lighting controls for Building 2 are of higher specification than in Building 1, relying both on daylight and occupancy sensors to switch lights on and off in different zones. This allows for the lighting fixtures in the perimeter of the building to be dimmed down when daylighting levels are sufficient to provide adequate lighting to the working areas near windows. In addition, the passive infra-red (PIR) sensors prevent lights from staying on when the building is unoccupied. This might be one of the main contributors to the fact that tenant electricity consumption in Building 2 is generally lower than in Building 1. With regards to catering facilities, each floor has a kitchen of a similar size and nature (consisting mainly of an instant hot water heater, a microwave, a dishwasher and a large fridge).

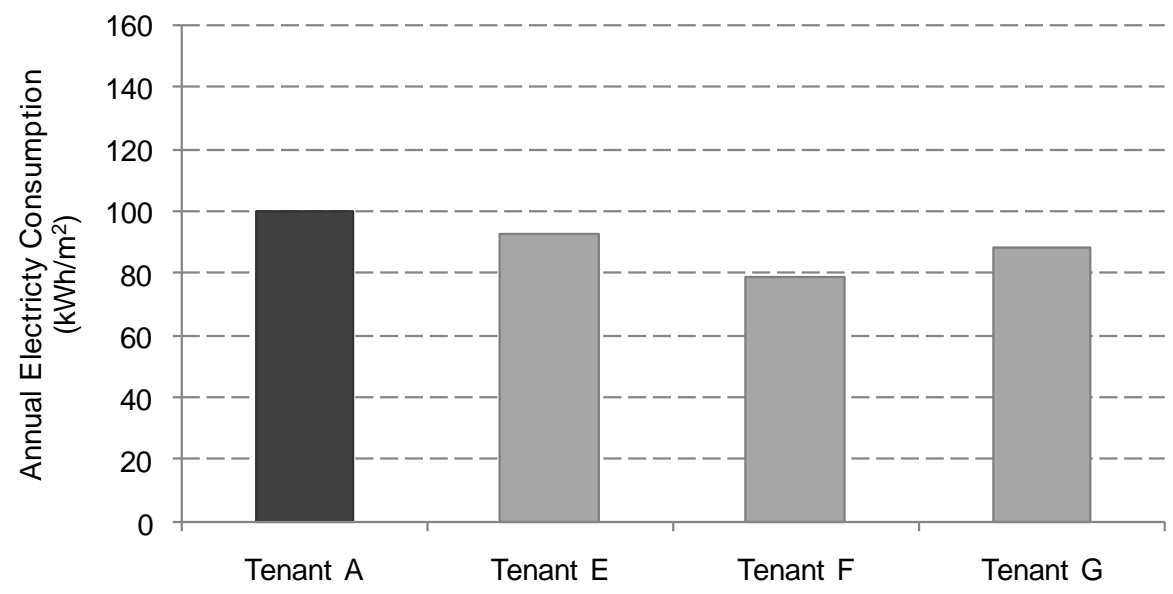

Figure 8: Annual electricity consumption per tenant in Building 2

As seen, the highest consumer (Tenant A) consumes approximately $30 \%$ more electricity than the lowest consumer (Tenant F). Further investigation into the causes of such variation revealed that the zone occupied by Tenant $F$ houses a call centre that operates only during fixed hours. This means that that unlike most of the other tenants, employees of Tenant $\mathrm{F}$ do not generally work beyond regular working hours, resulting in lower electricity consumption both due to lighting and small power. It is also worth noting that Tenant $F$ occupies a single zone that is mostly located in the perimeter of the building. Meanwhile, Tenants $E$ and $G$ undertake similar tasks, having similar equipment specification and office space layout. Together they occupy approximately $75 \%$ of the building's floor area and their numerous zones vary from open plan office spaces, to meeting rooms and seating areas.

Figure 9 illustrates the electricity consumption in each of the sub-metered zones within Building 2 (normalised by floor area). Once again the dark grey bars represent the zones occupied by Tenant A. Differently to Building 1, Tenant A's zones in 
Building 2 seem to consume almost exactly the same amount of electricity with virtually no variation between them. This is somewhat surprising considering that both zones are occupied and used in fairly different ways. Zone 3-5 houses a small kitchen, meeting rooms and a seating area, as well as open plan office spaces, whereas zone 3-2.2 is fully occupied by open plan office spaces. Considering the virtually identical electricity consumption in both zones, it is possible to assume that the increased use of electricity due to catering equipment is somewhat cancelled out by the additional seating area and the meeting rooms, where less electricity consumption is usually observed when compared to open plan office spaces. Another surprising observation from Figure 9 is that Tenant A's zones are not within the worst consuming zones, which might have been expected considering they were the highest consumers according to Figure 8. This would suggest that there is significant variation in electricity consumption on the zones occupied by the other tenants. It is worth mentioning that zone 3-2.1 is omitted from Figure 9 as it has been unoccupied for several months, and would not provide a fair comparison against the other zones.

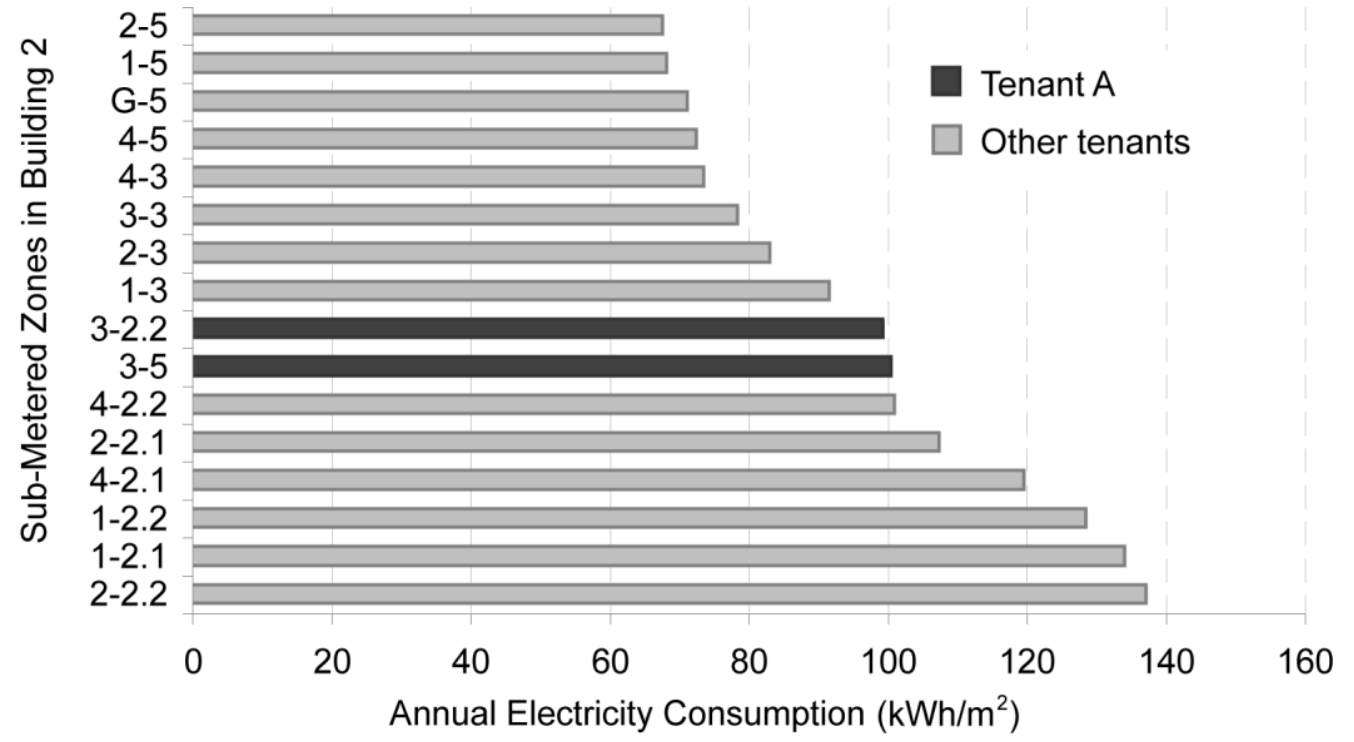

Figure 9: Electricity consumption in individual zones of Building 2

Figure 10 illustrates the electricity consumption by all tenants in Building 1 and Building 2. It also displays existing typical (TYP) and best-practice (BP) benchmarks for both lighting and small power in UK office buildings according to the Energy Consumption Guide $19^{[11]}$. Note that in Building 1 the lighting and small power are metered separately, but this is not the case in Building 2, which explains the different information provided in the figure. As seen, Tenant $A$ is the highest consumer in Building 2 and the lowest consumer in Building 1, but their electricity consumption is also fairly consistent in both buildings. With the exception of Tenant A, all Building 2 tenants are in the lower consuming half of the graph and similarly all Building 1 tenants are in the higher consuming half of the graph. This could be related to the fact that Building 2 has better lighting controls than Building 1, as previously discussed, which is further substantiated by the fact that all Building 2 tenants have lighting consumption below the typical benchmark.

Looking further into the consumption for Building 2 tenants, it is possible to see that there is significant variation in lighting consumption amongst the different tenants. Considering that the lighting specifications and controls are consistent throughout the entire building, this variation could be attributed to two elements: 1) hours of occupancy and 2) location of the zones (which determines the amount of daylighting 
available). Tenant $\mathrm{F}$, the lowest consuming tenant with regards to lighting, has a combination of both well-located zones and low hours of occupancy. They occupy a single zone in the building that is mostly located on the perimeter, and as previously discussed, Tenant $\mathrm{F}$ employees work for a smaller number of hours when compared to other tenants. They do however consume a significant amount of electricity for small power, comparable to that of the highest consumer in Building 2 (Tenant A). Meanwhile, the tenant with highest lighting consumption (Tenant $G$ ) also has the lowest small power consumption, suggesting that many of their zones are indeed occupied by meeting rooms and seating areas with low installed equipment densities.

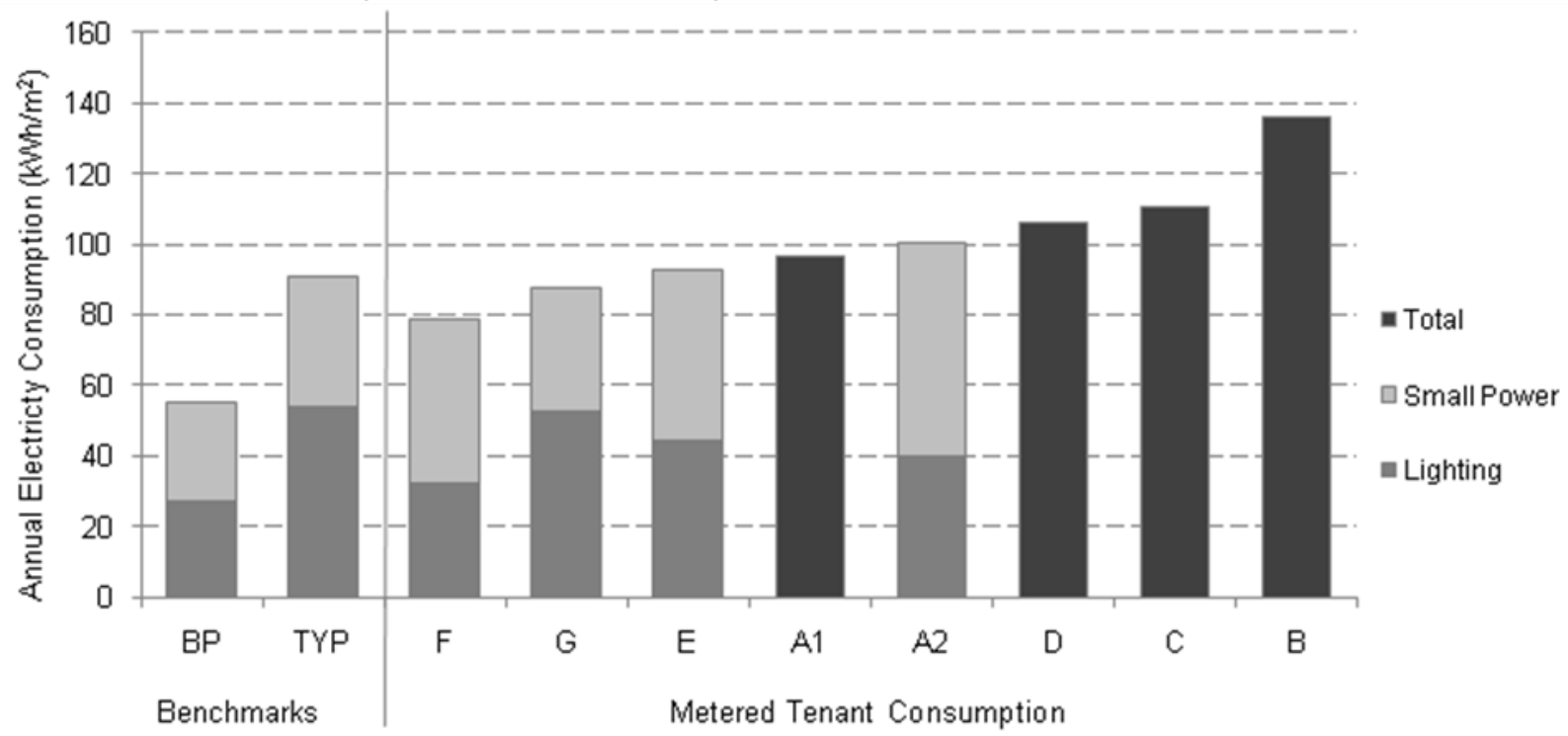

Figure 10: Annual electricity consumption by all tenants in both buildings

3.2 Half-Hourly Electricity Consumption

Figure 11 illustrates the half hourly electricity consumption in one of zones occupied by Tenant $A$ in Building 1 . The electricity consumption data is normalised by the floor area covered by the sub-meter being monitored and represents the instantaneous electricity demand in Watts per $\mathrm{m}^{2}$.

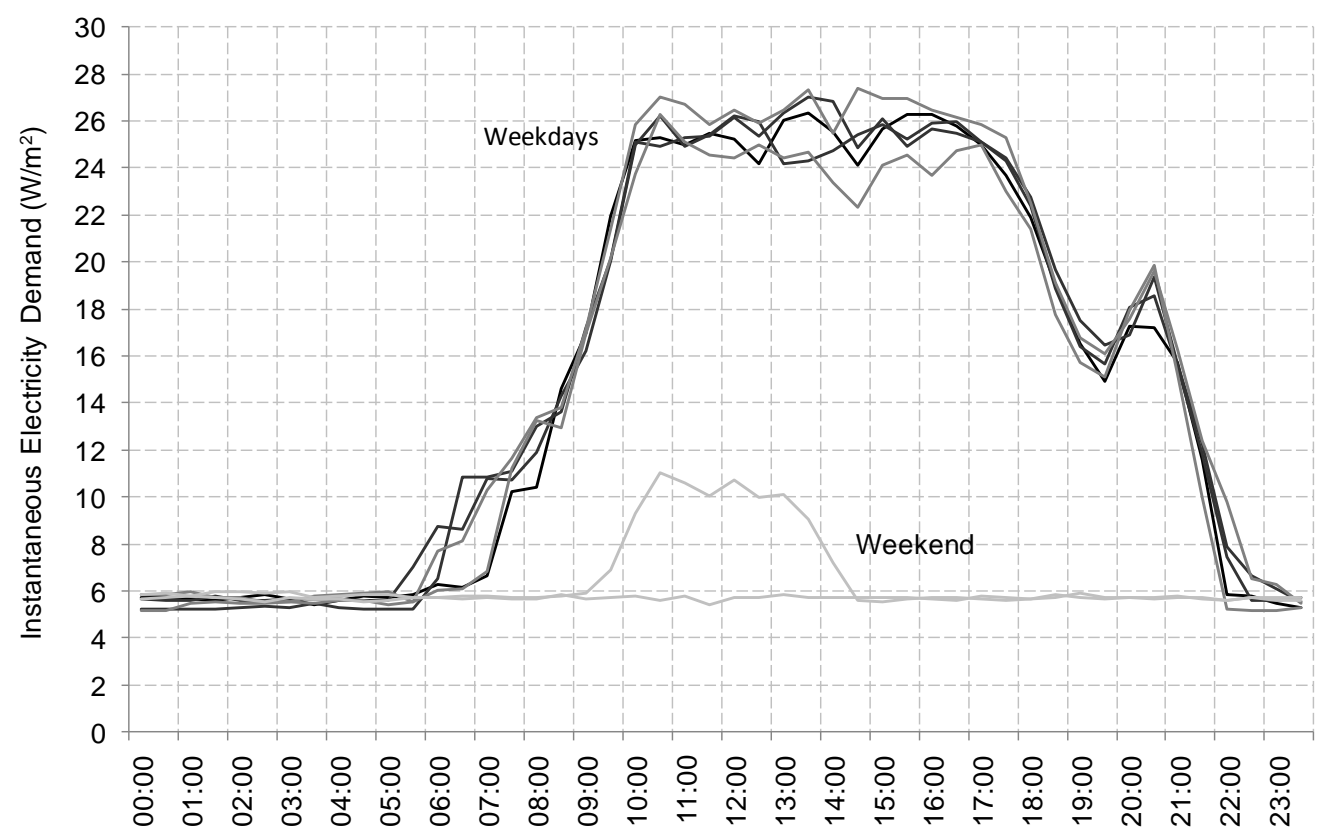

Figure 11: Half hourly electricity use by Tenant A in Building 1 
As seen the base load is approximately $6 \mathrm{~W} / \mathrm{m}^{2}$ outside working hours. The electricity demand starts to escalate around 06:00 peaking at approximately $26 \mathrm{~W} / \mathrm{m}^{2}$ by $10: 00$. This can be associated with the arrival of employees who trigger the motion sensors, turning on the lights. This will usually be followed by office/catering equipment being used. From 10:00 to 17:00 the demand remains fairly high, varying between 22-28 $\mathrm{W} / \mathrm{m}^{2}$, eventually decreasing to approximately $16 \mathrm{~W} / \mathrm{m}^{2}$ by $19: 30$. This can be associated with equipment being turned off as employees leave the office. A steep rise in the demand is then observed at approximately 20:30, followed by a fairly quick decrease, bringing the demand down to the base load at around 22:00. This late peak can be associated with the cleaning schedule of the building. It is assumed that the rise in demand is due to the use of vacuum cleaners as well as the dishwasher being turned on. The electricity demand during the weekend is fairly constant at a similar base load to the evenings. The only deviation occurs on Saturday between 9:00 and 15:00 when the electricity demand rises to approximately $10 \mathrm{~W} / \mathrm{m}^{2}$. This can be associated to a small number of employees going into the office to work.

For comparison, Figure 12 illustrates the half hourly electricity consumption profile for a zone occupied by Tenant A in Building 2. Similarly to Building 1, the electricity demand starts to escalate around 06:00, but it peaks slightly earlier, by 09:00. The peak demand is very similar to Building 1 at approximately $26 \mathrm{~W} / \mathrm{m}^{2}$, and variations throughout the day are of very similar nature and size. A steep decrease in demand is observed around 19:00 and unlike Building 1 there is no cleaning peak following the departure of the employees. This is due to earlier cleaning schedule in building 2 in combination with employees leaving between 17:30 and 19:30. This results in a fairly smooth decrease in demand at the end of each working day. Similarly to Building 1, there is also a small peak in demand on Saturday due to some employees coming into the office.

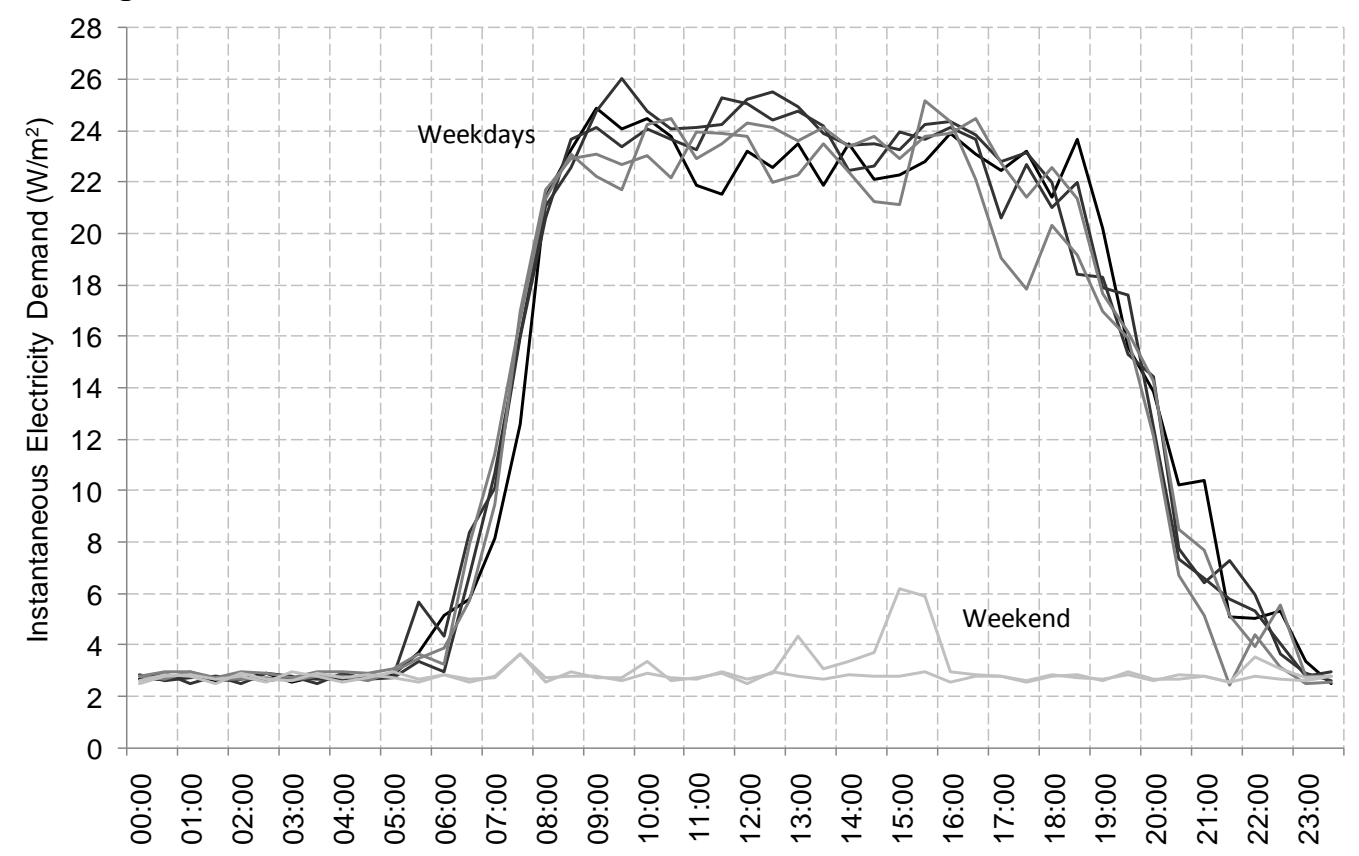

Figure 12: Combined half hourly electricity use by Tenant A in Building 2

\subsection{Electricity Consumption by Different Equipment}

The TM22 assessment carried out in Building 1 allowed for a detailed analysis of the electricity consumption by different small power equipment used throughout the building. This was further enhanced by the use of plug monitors connected to each individual piece of equipment, monitoring their instantaneous electricity demand, 
allowing for assumptions on nameplate-ratings and usage factors to be eliminated from the TM22 methodology. Figure 13 illustrates the annual electricity consumption by each of the small power equipment monitored as part of the study. It covers the installed equipment in the zones occupied by Tenant $A$ in Building 1, and is normalised by floor area. As seen, desktops and laptops are responsible for the largest share of the electricity consumption at $17.5 \mathrm{kWh} / \mathrm{m}^{2} /$ year, followed closely by computer screens at $14.6 \mathrm{kWh} / \mathrm{m}^{2} /$ year. Photocopiers are also responsible for a significant portion of the electricity consumption, at $6.2 \mathrm{kWh} / \mathrm{m}^{2} /$ year, but their impact is only about $30 \%$ of that of computers. Coffee machines and fridges consume a similar amount at approximately $2 \mathrm{kWh} / \mathrm{m}^{2} /$ year. Desk lamps, microwave ovens and dishwashers all consume less than $1 \mathrm{kWh} / \mathrm{m}^{2} /$ year. These results demonstrates that power management functions for computers and screens, as well as behaviour change campaigns aimed at getting employees to switch off their computers at the end of the day could have a significant impact on electricity consumption.

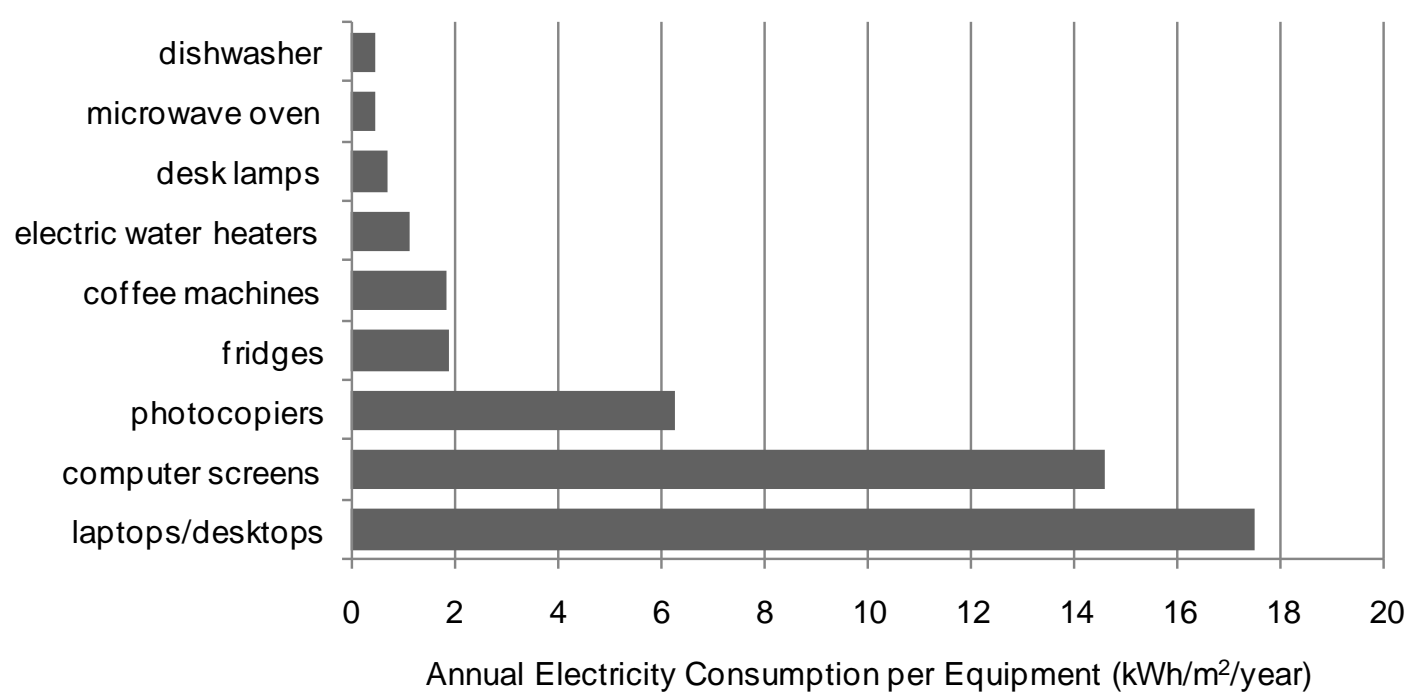

Figure 13: Annual electricity use per equipment by Tenant $A$ in Building 1

\subsection{Conclusion}

This paper has discussed the existence of a gap between predicted and measured energy consumption in non-domestic buildings. It highlighted that a significant lack of information regarding actual energy consumption in buildings might be a leading cause in this performance gap. Aiming to address this issue, two case studies were presented whereby detailed electricity consumption data for lighting and small power in office buildings were analysed and compared.

Key findings from the study highlighted a significant variation in electricity consumption by the different tenant in both buildings. Tenants in Building 2 generally consumed less electricity than those occupying Building 1 and that can be partially attributed to better lighting controls in the former. In addition, variations in workstation density and office space layout were also seen to contribute to the variations in electricity consumption. Management decisions, such as the running of IT updates outside of occupancy hours, were seen to have a significant impact on electricity use, having been observed in the highest consuming tenant. Meanwhile, tenants with fixed working hours were seen to have significantly lower consumption of electricity due to lighting. The analysis of data for Tenant $A$, which occupied zones in both buildings, demonstrated that the attitudes and behaviour of a company might transcend the immediate surroundings of the building being occupied. Similar 
electricity consumption profiles suggest that management protocols and behaviours might have more impact on energy consumption than previously anticipated.

Overall the study has highlighted the need for better understanding of occupancy patterns and behaviour in office buildings. Variations in the electricity consumption of different tenants occupying the same building have demonstrated that modelling software would need to account for different occupancy patterns and behaviours if realistic predictions are to be achieved.

\subsection{Future Work}

This paper has identified a need for further understanding of the impact of occupant and management behaviour on electricity consumption in buildings. As such, future work will include further monitoring of different office buildings occupied by diverse types of tenants. It is envisaged that a survey will be developed for both occupants and facilities managers to be distributed in buildings being monitored as part of this research. These will be aimed at understanding the impact of varying attitudes and behaviours regarding energy use in buildings, with the ultimate aim of determining the impact of these behaviours on the overall energy consumption of buildings. Information gathered from the surveys will be used to develop evidence based benchmarks for energy consumption in office buildings. These will include a 'tailoring' component allowing the benchmarks to be adjusted according to profiles of occupancy and management behaviour, as well as workstation density and the specification of energy consuming equipment. It is expected that these benchmarks will inform designers about the impact of each of these parameters on the measured energy consumption of buildings, and support efforts to reduce energy use.

\subsection{Acknowledgements}

The corresponding author would like to thank the EPSRC, Loughborough University and AECOM for funding this research.

\section{References}

${ }^{1}$ Bordass, B., Cohen, R., Standeven, M. \& Leaman, A., 2001. "Assessing Building Performance in Use 3: Energy Performance of Probe Buildings". Building Research and Information, vol. 29, no. 2, pp. 114-128.

${ }^{2}$ CarbonBuzz website: http://www.carbonbuzz.org [accessed on 05/05/2011].

${ }^{3}$ Hamilton, I., Steadman, P. \& Bruhns, H., 2011. "CarbonBuzz - Energy Data Audit". UCL Energy Institute, July 2011.

${ }^{4}$ Menezes, A. C., Cripps, A., Bouchlaghem, D. \& Buswell, R., 2011. Predicted vs. Actual Energy Performance of Non-Domestic Buildings: Proceedings of the Third International Conference on Applied Energy - Perugia, Italy, pp 1225-1240.

${ }^{5}$ Lowe, R. \& Oreszczyn, T., 2008. "Regulatory Standards and Barriers to Improved Performance for Housing”. Energy Policy, vol. 36, pp. 4475-4481. 
${ }^{6}$ Oreszczyn, T. \& Lowe, R., 2010. "Challenges for energy and buildings research: objectives, methods and funding mechanisms". Building Research and Information, vol 38, issue 1, pp 107-122.

${ }^{7}$ CIBSE, 2006. CIBSE TM22: Energy Assessment and Reporting. London, UK.

${ }^{8}$ CIBSE, 2006. CIBSE TM22: Energy Assessment and Reporting. London, UK.

${ }^{9}$ http://www.expresshire.net/_includes/docs/n9ymbsEk.pdf [accessed on 21/05/2011]

${ }^{10}$ http://www.plogginternational.com/applications.shtml [accessed on 02/06/2011].

${ }^{11}$ BRECSU, 2000. Energy Consumption Guide 19: Energy use in offices. Building Research Energy Conservation Support Unit, Watford, UK. 